\title{
Effect of dexmedetomidine combined with sufentanil on preventing emergence agitation in children receiving sevoflurane anesthesia for cleft palate repair surgery
}

\author{
KE LUO ${ }^{1}$, JUN-MEI XU ${ }^{1}$, LIN CAO ${ }^{1}$ and $\mathrm{JU} \mathrm{GAO}^{2}$ \\ ${ }^{1}$ Department of Anesthesiology, The Second Xiangya Hospital of Central South University, Changsha, \\ Hunan 410011; ${ }^{2}$ Department of Anesthesiology, Clinical Medical School of Yangzhou University, \\ Subei People's Hospital of Jiangsu, Yangzhou, Jiangsu 225001, P.R. China
}

Received April 13, 2016; Accepted March 17, 2017

DOI: $10.3892 /$ etm.2017.4660

\begin{abstract}
The aim of the present study was to observe whether dexmedetomidine (DEX) combined with sufentanil decreased emergence agitation (EA) in children receiving sevoflurane anesthesia for cleft palate repair surgery. Children undergoing elective cleft palate repair surgery were randomly allocated into the DEX + sufentanil group (group DS; n=50) and the normal saline + fentanyl group (group SF; $n=50$ ). Patients in group DS were treated with $0.5 \mu \mathrm{g} / \mathrm{kg}$ DEX prior to induction of anesthesia, whereas patients in group SF received an equal volume of normal saline. Sufentanil $(0.2 \mu \mathrm{g} / \mathrm{kg})$ was administered to induce anesthesia, and $30 \mathrm{~min}$ before the end of surgery for patients in group DS. Fentanyl $(2 \mu \mathrm{g} / \mathrm{kg})$ was administered at the same time point for patients in group SF. Mean arterial pressure (MAP), heart rate (HR), duration of surgery and anesthesia, and the dosage of remifentanil were assessed. EA score, Pediatric Anesthesia Emergence Delirium (PAED) score and the Children and Infants Postoperative Pain Scale (CHIPPS) score were documented every $15 \mathrm{~min}$ in the post-anesthesia care unit (PACU). The number of cases requiring fentanyl $(1 \mu \mathrm{g} / \mathrm{kg})$ and the recovery profile data were analyzed. Compared with group DS $(\mathrm{P}<0.05)$ and the baseline $(\mathrm{P}<0.05), \mathrm{HR}$ and MAP were significantly increased in group SF immediately following tracheal intubation and extubation. Mean values of maximum EA, PAED and CHIPPS scores were significantly reduced in group DS compared with group $\mathrm{SF}$ at $0(\mathrm{P}<0.01), 15(\mathrm{P}<0.05)$, and $30 \mathrm{~min}(\mathrm{P}<0.05)$ after arrival at PACU. The incidence of EA in group SF was significantly
\end{abstract}

Correspondence to: Dr Ju Gao, Department of Anesthesiology, Clinical Medical School of Yangzhou University, Subei People's Hospital of Jiangsu, 98 Nan Tong Western Road, Yangzhou, Jiangsu 225001, P.R. China

E-mail: happygezi81@163.com

Key words: dexmedetomidine, sufentanil, emergence agitation, sevoflurane anesthesia, pediatric anesthesia emergence delirium, children and infants postoperative pain increased compared with group DS $(\mathrm{P}<0.05)$. The dosage of remifentanil during the surgery and the number of cases requiring fentanyl $(1 \mu \mathrm{g} / \mathrm{kg})$ in group DS were significantly decreased compared with group SF $(\mathrm{P}<0.05)$. The findings of the present study suggested that DEX combined with sufentanil was able to effectively decrease the incidence of EA in children receiving sevoflurane anesthesia for cleft palate repair surgery.

\section{Introduction}

Cleft palate is a common congenital malformation in children. The American Cleft Palate-craniofacial Association recommends that primary cleft palate surgery should ideally be performed within 12-18 months after birth (1). However, this would increase the potential risk of airway obstruction during the recovery period after general anesthetization for cleft palate repair surgery due to the younger age and association with potent stimulation of oropharyngeal pain, tissue swelling, blockage of blood or secretions and gauze oppression $(2,3)$. Simultaneously, these factors may lead to respiratory depression, restlessness, nausea and vomiting, and increase the days of hospitalization and hospital costs (4). Other factors, such as anticipation of postoperative pain, separation from the family, incapacity, loss of independence, fear of surgery and fear of death may lead to emergence agitation (EA) (5).

Currently, sevoflurane has been widely used in pediatric anesthesia, particularly for infants, predominantly because it is less pungent and has a more rapid onset and offset than other potent inhaled agents due to lower solubility in blood, a relative lack of airway irritation and greater hemodynamic stability $(6,7)$. However, numerous studies have demonstrated that sevoflurane anesthesia in patients had a higher risk of postoperative agitation, particularly in children $(8,9)$. The incidence rate of EA varies depending on the type and severity of EA. The incidence of EA is relatively high regardless of the way of the definition; $33 \%$ of the time when defining a high threshold for agitation, and $80 \%$ of the time when using a lower threshold in children after sevoflurane anesthesia without surgery (10). The exact mechanisms of 
sevoflurane leading to postoperative agitation in children are unclear. Relevant factors include age, pain stimulation and surgical methods (11). Several currently available randomized controlled trials have illustrated the effectiveness of dexmedetomidine (DEX) in the prevention of sevoflurane-related EA incidence, as well as severe EA (12). Administration of $0.2 \mu \mathrm{g} / \mathrm{kg}$ sufentanil after induction of anesthesia was able to reduce EA in children receiving sevoflurane anesthesia for adenotonsillectomy compared with $2 \mu \mathrm{g} / \mathrm{kg}$ fentanyl (13). However, the views on the influence of the agents on EA remain controversial.

Various studies have focused on the application of DEX and sufentanil separately regarding sevoflurane anesthesia in children; however, research on the application of DEX combined with sufentanil is limited. In the present study, the clinical efficacy of DEX combined with sufentanil in children receiving sevoflurane anesthesia for cleft palate repair surgery was investigated.

\section{Materials and methods}

Ethics statement and patients. The present study was approved by the Bioethics Committee at the Second Xiangya Hospital of Central South University (no. 2012045; Changsha, China). Following internal review board approval and parental informed consent, 100 ASA physical status I-II (14) children (male/female: $42 / 58$; $1-5$ years old) who were scheduled to undergo sevoflurane anesthesia for cleft palate repair surgery were included. Following approval by the Ethics Committee of the Second Xiangya Hospital of Central South University, the study was prospectively conducted between January 2013 and October 2015. Informed consent was obtained from all individual participants included in the study. Exclusion criteria included the following: Lack of consent; disorders of the respiratory, circulatory or nervous system; known adverse reactions to DEX and sufentanil; a history of adverse reactions to general anesthesia, difficulties with airways, breath-holding and/or postoperative bleeding; or illness that would be associated with agitation, such as seizures or schizophrenia. Children were randomly allocated into the DEX + sufentanil group (group DS; $n=50$ ) or the normal saline + fentanyl group (group SF; n=50). Subjects were randomized by the use of a computer-generated table of random numbers to receive DEX or placebo.

Anesthetic management. Both groups of children were fasted from solid foods for $6 \mathrm{~h}$ prior to the procedure; clear liquids were permitted until $2 \mathrm{~h}$ prior to admission to the operating room (OR). A total of $0.01 \mathrm{mg} / \mathrm{kg}$ penehyclidine hydrochloride (Lisite Biopharmaceuticals Co., Ltd., Chengdu, China) was administered intravenously to all children as soon as intravenous access was established prior to admission into the OR. A total of $0.5 \mu \mathrm{g} / \mathrm{kg} \mathrm{DEX}$ (diluted to $20 \mathrm{ml}$; Hengrui Biopharmaceuticals Co., Ltd., Lianyungang, China) was administered intravenously over a 10 -min period prior to induction of anesthesia in group DS, and the patients in group SF received an equal volume of normal saline. Intravenous induction of anesthesia using midazolam (0.05-0.1 mg/kg; Enhua Pharmaceutical Group Co., Ltd., Xuzhou, China), propofol (2.0 mg/kg; Fresenius Kabi AB
Pharmaceutical Group Co., Ltd., Beijing, China) and cisatracurium (0.15 mg/kg; Dongying Pharmaceutical Group Co., Ltd., Jiangsu, China) was performed. Sufentanil $(0.2 \mu \mathrm{g} / \mathrm{kg}$; Renfu Pharmaceutical Group Co., Ltd., Yichang, China) was administered intravenously after induction and $30 \mathrm{~min}$ before the end of cleft palate repair for patients in group DS. Fentanyl ( $2 \mu \mathrm{g} / \mathrm{kg}$; Renfu Pharmaceutical Group Co., Ltd.) was administered intravenously at the same time for patients in group SF. Tracheal intubation (Meinuo Medical Appliances Co., Ltd., Suzhou, China) was performed by an attending doctor after loss of consciousness and the observer assessment of alertness and sedation (OAAS) score was $\leq 3$ (15). Dexamethasone (0.1 mg/kg; Fengyuan Pharmaceutical Group Co., Ltd., Anhui, China) was administered after anesthesia induction to reduce post-operative nausea and vomiting. Cisatracurium (0.1 mg/kg; Dongying Pharmaceutical Group Co., Ltd.) was selectively administered according to maintenance time of muscle relaxant drugs and surgical time. Anesthesia was maintained with $2 \%$ volume inhalation of sevoflurane (Yapei Pharmaceutical Group Co., Ltd., Shanghai, China) and remifentanil (Rennfu Pharmaceutical Group Co., Ltd.) 1.5-2.5 ng/ml target-controlled infusion (TCI). All anesthetic administrations were terminated $10 \mathrm{~min}$ before the end of surgery. All pharmacological agents used in the present study were prepared and administrated by the anesthesiologists who were blinded to the details of the study.

Anesthesia management. Pressure control ventilation mode was used to maintain breathing, and set inspiratory pressure (10-15 $\mathrm{mmHg})$, oxygen flow $(2 \mathrm{l} / \mathrm{min})$, respiratory ratio (1:1.5), respiratory rate (18-30 times/min) and the partial pressure of end-tidal carbon dioxide $\left(\mathrm{PETCO}_{2} ; 35-45 \mathrm{mmHg}\right)$. Anesthesia was maintained with sevoflurane $2 \%$ volume inhalation and remifentanil 1.5-2.5 ng/ml TCI to control the change of mean arterial pressure (MAP) and heart rate (HR) to within $25 \%$ of the baseline (baseline valued were obtained from patients prior to any medication and surgery). MAP, HR, peripheral capillary oxygen saturation $\left(\mathrm{SpO}_{2}\right)$ and $\mathrm{PETCO}_{2}$ during the surgery were monitored. The depth of sedation was monitored using the A-2000 XP bispectral index monitor (Aspect Medical Systems, Inc., Norwood, MA, USA). Children were sent to the post-anesthesia care unit (PACU) after surgery, where EA scores were observed and recorded. An emergence agitation scale (EAS) was measured every $15 \mathrm{~min}$ in the PACU (16). Aono's scale (17) of 3 or 4 were classified as severe EA. Tracheal extubation was performed with careful suction when spontaneous breathing ventilation (indicated when $\mathrm{PETCO}_{2}$ reached $35 \mathrm{mmHg}$ ) was achieved and children regained gag or cough reflex. Patients without pain that were calm and with a modified Aldrete score $>10$ were transferred to the ward (18). The time at which these criteria were met was also recorded. The Children and Infants Postoperative Pain Scale (CHIPPS) was adopted to determine whether fentanyl at $1 \mu \mathrm{g} / \mathrm{kg}$ was administered (CHIPPS pain score $>5$ ) as rescue medication or not (19). Time to extubation was defined from admission to PACU until the trachea was extubated. The recovery time was defined as the time between the admission to and discharge from PACU. EA, Pediatric Anesthesia Emergence Delirium (PAED) (20) and CHIPPS scores were documented every $15 \mathrm{~min}$ in PACU by a well-trained PACU nurse who was blinded to the study. 


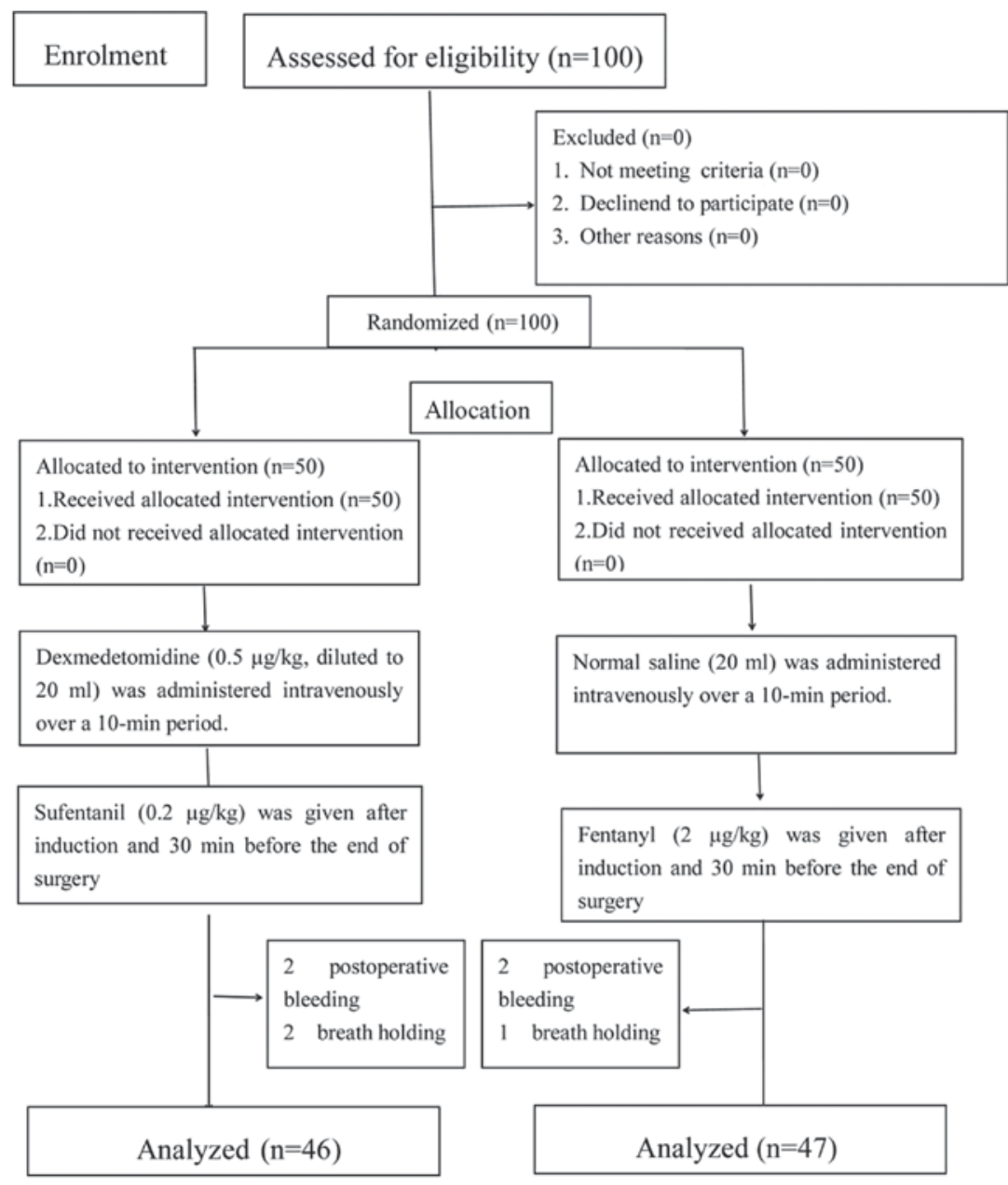

Figure 1. Randomization of patients into dexmedetomidine + sufentanil or normal saline + fentanyl groups.

Aono's scale and PAED scale. Aono's scale (17) was used to evaluate post-operative behaviour $(1=$ calm; $2=$ not calm but could be easily consoled; $3=$ moderately agitated or restless and not easily calmed; and $4=$ combative, excited or disoriented, thrashing. around). Severe EA was defined as an Aono's score of 3 or 4. PAED scale was defined as follows: 1, the child makes eye contact with the caregiver; 2 , the child's actions are purposeful; 3 , the child is aware of his/her surroundings; 4 , the child is restless; and 5, the child is inconsolable.

Observed parameters. MAP and HR at T1 (entering the OR), T2 (before induction of anesthesia), T3 (immediately following tracheal intubation), T4 (end of the surgery) and T5 (immediately following tracheal extubation) were recorded. Duration of surgery and anesthesia and the dosage of remifentanil was assessed. EA, PAED and CHIPPS scores were documented every $15 \mathrm{~min}$ in the PACU. The number of cases that required fentanyl $(1 \mu \mathrm{g} / \mathrm{kg})$ and the recovery profile data were analyzed.

Statistical analysis. Data were presented as the mean \pm standard deviation. Statistical analyses were performed using the statistical package, SPSS v. 16.0 for Windows (SPSS, Inc., Chicago, IL, USA). Patient characteristics were compared using one-way analysis of variance with Kruskal-Wallis post hoc tests and $\chi^{2}$ test where appropriate. Differences in the incidence of severe EA among the groups were analyzed using $\chi^{2}$ test with Fisher's exact test correction. Differences in PAED and CHIPPS scores among groups were analyzed using the Kruskal-Wallis test with Bonferroni's correction. $\mathrm{P}<0.05$ was considered to indicate a statistically significant difference.

\section{Results}

Excluded patients. A total of 100 patients were enrolled into the present study, of which 93 fulfilled the inclusion criteria. A total of 7 patients were excluded. The excluded patients included 4 patients from group DS and 3 patients from group SF, due to breath-holding and postoperative bleeding (Fig. 1).

Patient demographics and duration of surgery and anesthesia. Patient demographics and duration of surgery and anesthesia are presented in Table I. No significant differences were identified in patient demographics or duration of surgery and anesthesia among the two groups.

Anesthetic data. HR and MAP were maintained within 25\% of the baseline in both groups throughout anesthesia (Fig. 2). HR and MAP were significantly increased in group SF immediately following tracheal intubation and extubation compared with group DS $(\mathrm{P}<0.05)$ and the SF baseline $(\mathrm{P}<0.05)$. HR and 
Table I. Patient demographics and duration of surgery and anesthesia.

\begin{tabular}{lcrr}
\hline & \multicolumn{2}{c}{ Group } \\
\cline { 2 - 3 } Parameter & DS (n=46) & SF (n=47) & \\
\hline Gender & & & 0.21 \\
Male, $\mathrm{n}(\%)$ & $18(39.1)$ & $20(42.6)$ & 0.37 \\
Female, $\mathrm{n}(\%)$ & $28(61.9)$ & $27(57.4)$ & 0.65 \\
Age, years & $2.9 \pm 1.2$ & $12.0 \pm 1.0$ & 0.71 \\
Weight, $\mathrm{kg}$ & $13.1 \pm 2.5$ & $106.5 \pm 5.8$ & 0.79 \\
Duration of anesthesia, min & $105.4 \pm 7.5$ & $92.0 \pm 5.3$ & 0.43 \\
Duration of surgery, min & $94.1 \pm 6.1$ & & \\
\hline
\end{tabular}

Data are presented as the mean \pm standard deviation. No significant differences in demographic parameters, duration of surgery and anesthesia between the groups were indicated. Group DS, dexmedetomidine + sufentanil group; Group SF, normal saline + fentanyl group.
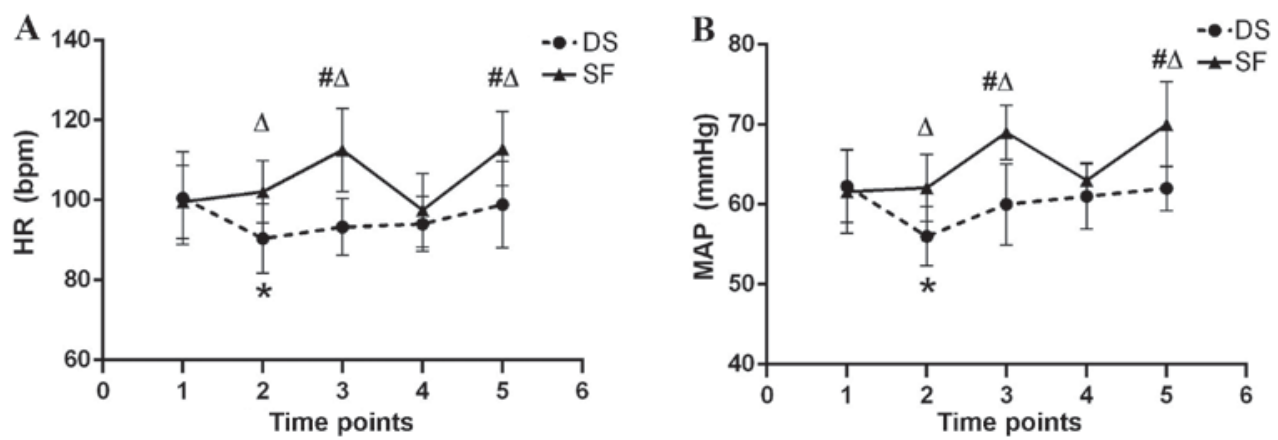

Figure 2. (A) HR and (B) MAP recordings at various time points: (1) Entering the OR; (2) before induction of anesthesia; (3) immediately following tracheal intubation; (4) end of the surgery; and (5) immediately following tracheal extubation. Data are presented as the mean \pm standard deviation. ${ }^{*} \mathrm{P}<0.05$ vs. the baseline (HR and MAP of patient when entering the operating room) in Group DS; ${ }^{~} \mathrm{P}<0.05$ vs. the baseline in Group SF; ${ }^{\Delta} \mathrm{P}<0.05$ vs. Group DS at the same time point. Group DS, dexmedetomidine + sufentanil group; Group SF, normal saline + fentanyl group; HR, heart rate; MAP, mean arterial pressure.

MAP at T2 (before induction of anesthesia) were significantly increased in group DS compared with the DS baseline $(\mathrm{P}<0.05)$.

Postoperative pain and severe EA. The incidence of severe EA (Aono's scale 3 or 4 ) was $2 / 46(4.3 \%)$ in the DS group and $26 / 47(55.3 \%)$ in the SF group $(\mathrm{P}<0.01)$. The incidence of EA was $4 / 46(8.6 \%)$ in the group DS and 36/47 (76.6\%) in the SF group $(\mathrm{P}<0.01$; Table II). The incidence of severe EA and EA was significantly decreased in the DS group compared with the group $\mathrm{SF}(\mathrm{P}<0.01)$. The mean maximum PAED score was significantly decreased in group DS compared with group SF (7.2 \pm 4.3 vs. $11.8 \pm 5.1$, respectively; $\mathrm{P}<0.01$; Table II). The mean maximum CHIPPS score was also significantly decreased in Group DS compared with Group SF (3.0 2.5 vs. $6.2 \pm 3.1$, respectively; $\mathrm{P}<0.01$; Table II). The dosage of remifentanil required in group $\mathrm{SF}$ was significantly larger than that required in group DS (279.6 \pm 32.8 vs. $191.25 \pm 28.5$, respectively; $\mathrm{P}<0.01$; Table II). The mean maximum EA, PAED and CHIPPS scores were significantly decreased in Group DS compared with Group $\mathrm{SF}$ at $0(\mathrm{P}<0.01), 15(\mathrm{P}<0.05)$ and $30 \mathrm{~min}(\mathrm{P}<0.05)$ after arrival at PACU (Fig. 3).

Recovery profiles. The recovery profiles were listed in Table III. A total of 5 (10.8\%) children in group DS required rescue fentanyl doses of $1 \mu \mathrm{g} / \mathrm{kg}$. This was significantly higher than group SF, in which 29 (61.7\%) children required rescue fentanyl doses of $1 \mu \mathrm{g} / \mathrm{kg}(\mathrm{P}<0.01$; Table III). However, no significant difference was indicated between the two groups in time to tracheal extubation, recovery time and Aldrete score in PACU. There was no significant difference in the incidence of side effects between the two groups, such as coughing, chest wall rigidity, and postoperative nausea and vomiting. Two cases of postoperative bleeding and two cases of breath-holding occurred in the DS group, whereas the SF group had two cases of postoperative bleeding and one case of breath-holding.

\section{Discussion}

The present study was performed to evaluate whether DEX combined with sufentanil was able to optimize the efficacy of sevoflurane anesthesia in children receiving cleft palate repair surgery. The present findings indicated that DEX combined with sufentanil effectively inhibited intubation and extubation response of children receiving sevoflurane anesthesia for cleft palate repair surgery, maintained greater hemodynamic stability, reduced the incidence of EA, reduced the dose of remifentanil and reduced the requirement of fentanyl $1 \mu \mathrm{g} / \mathrm{kg}$ 
Table II. Recovery profile of patients based on EA, CHIPPS and PAED scores, and the dosage of remifentanil required.

\begin{tabular}{lcrr}
\hline & \multicolumn{2}{c}{ Group } & \\
\cline { 2 - 3 } Assessment criteria & DS $(\mathrm{n}=46)$ & SF $(\mathrm{n}=47)$ & P-value \\
\hline Severe EA, $\mathrm{n}(\%)$ & $2(4.3)$ & $26(55.3)$ & $<0.01$ \\
EA, $\mathrm{n}(\%)$ & $4(8.6)$ & $36(76.6)$ & $<0.01$ \\
CHIPPS maximum score & $3.0 \pm 2.5$ & $6.2 \pm 3.1$ & $<0.01$ \\
CHIPPS score $>6, \mathrm{n}(\%)$ & $6(13.0)$ & $31(66.0)$ & $<0.01$ \\
PAED maximum score & $7.2 \pm 4.3$ & $11.8 \pm 5.1$ & $<0.01$ \\
PAED $>11, \mathrm{n}(\%)$ & $3(6.5)$ & $38(80.9)$ & $<0.01$ \\
Dosage of remifentanil, $\mu \mathrm{g}$ & $191.5 \pm 28.5$ & $279.6 \pm 32.8$ & $<0.01$ \\
\hline
\end{tabular}

The CHIPPS and PAED maximum scores, and the dosage of remifentanil are expressed as the mean \pm standard deviation. EA, emergence agitation; CHIPPS, Children and Infants Postoperative Pain Scale; PAED, Pediatric Agitation and Emergence Delirium; Group DS, dexmedetomidine + sufentanil group; Group SF, normal saline + fentanyl group.

Table III. Recovery profiles of patients.

\begin{tabular}{lccr}
\hline & \multicolumn{2}{c}{ Group } \\
\cline { 2 - 3 } Assessment criteria & DS (n=46) & SF (n=47) & P-value \\
\hline Time to extubation, min & $10.6 \pm 4.1$ & $9.7 \pm 3.9$ & 0.45 \\
Recovery time, min & $46.7 \pm 12.3$ & $43.2 \pm 15.6$ & 0.41 \\
Aldrete score & $7.8 \pm 1.1(6-10)$ & $8.2 \pm 1.5(6-10)$ & 0.51 \\
Patients requiring 1 $\mu \mathrm{g} / \mathrm{kg}$ fentanyl rescue doses, $\mathrm{n}(\%)$ & $5(10.8)$ & $29(61.7)$ & $<0.01$ \\
Side effects & & & 0.89 \\
Cough, $\mathrm{n}(\%)$ & $1(2.2)$ & $2(4.3)$ & 0.91 \\
Chest wall rigidity, $\mathrm{n}(\%)$ & $1(2.2)$ & $0(0)$ & 0.94 \\
Postoperative nausea & $3(6.5)$ & $4(8.5)$ & \\
and vomiting, $\mathrm{n}(\%)$ & & & \\
\hline
\end{tabular}

Time to extubation, recovery time and Aldrete scores are expressed as the mean \pm standard deviation. Group DS, dexmedetomidine + sufentanil group; Group SF, normal saline + fentanyl group.
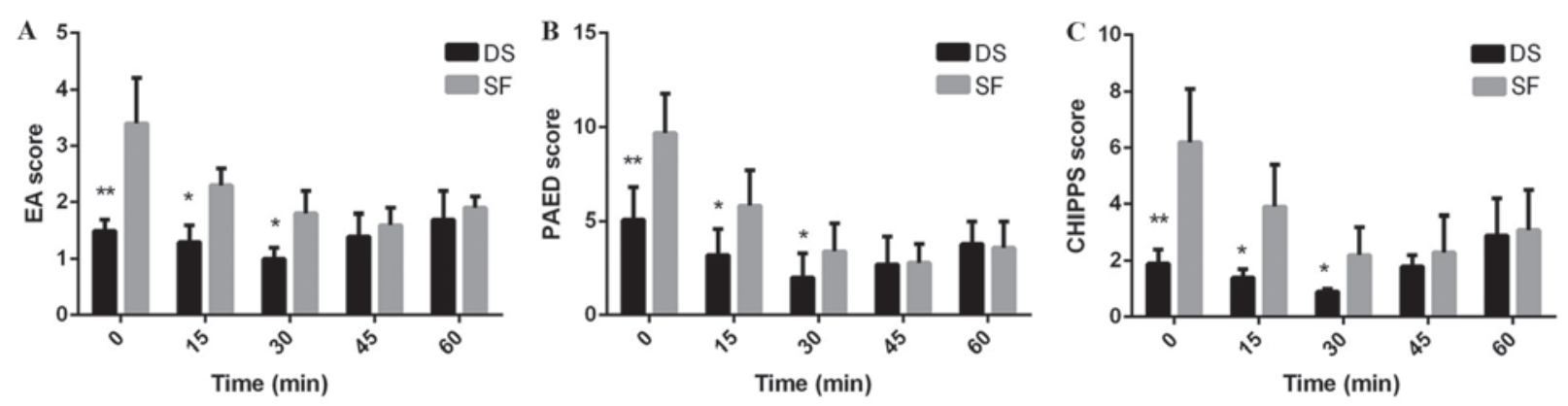

Figure 3. Postoperative EA and CHIPPS scores of patients in post-anesthesia care unit. (A) EA, (B) PAED and (C) CHIPPS scores were determined. Data are presented as the mean \pm standard deviation. ${ }^{*} \mathrm{P}<0.05$ and ${ }^{* *} \mathrm{P}<0.01$ vs. Group SF. Group DS, dexmedetomidine + sufentanil group; Group SF, normal saline + fentanyl group; EA, emergence agitation 5-point scale; PAED, Pediatric Anesthesia Emergence Delirium; CHIPPS, Children and Infants Postoperative Pain Scale.

treatment. However, DEX combined with sufentanil did not significantly alter the time to extubation or the recovery time.
The exact causes of postoperative agitation in children following general anesthesia are not clear. However, several associated risk factors associated with EA have been indicated, 
including preschool age, pain, preoperative anxiety, personal character of the patient, too-rapid awakening, otolaryngologic procedures (cleft palate repair surgery) and the use of sevoflurane (21-24). Although sevoflurane is associated with a high incidence of EA, it has been widely used as a sole agent for pediatric anesthesia (25). Numerous studies have shown that benzodiazepines, barbiturates and opioids contribute to behavioral disturbances after sevoflurane general anesthesia $(26,27)$.

The predominant outcome of the present study was that DEX combined with sufentanil significantly reduced the incidence of EA by $68 \%$ compared with saline and fentanyl treatment (8.6 vs. $76.6 \%$, respectively). When severe EA was defined as an Aono's scale of 3 or 4, DEX combined with sufentanil significantly reduced the incidence of severe EA by $51 \%$ compared with saline and fentanyl treatment (4.3 vs. $55.3 \%$, respectively). A previous study by Özcengiz et al (28) demonstrated that oral melatonin $(0.1 \mathrm{mg} / \mathrm{kg}), \operatorname{DEX}(2.5 \mu \mathrm{g} / \mathrm{kg})$ and midazolam $(0.5 \mathrm{mg} / \mathrm{kg})$ reduced the incidence of EA in children after sevoflurane anesthesia and that the incidence of EA among the three groups was similar. Furthermore, intranasal DEX $(1 \mu \mathrm{g} / \mathrm{kg})$ and midazolam $(0.2 \mathrm{mg} / \mathrm{kg})$ were demonstrated to be equally effective in decreasing anxiety at parental separation; however, midazolam was superior in terms of providing satisfactory conditions during mask induction (29). A study by Tan et al (30) revealed that intraoperative continuous infusion of low-dose $\operatorname{DEX}(0.2 \mu \mathrm{g} / \mathrm{kg} / \mathrm{h})$ was able to reduce EA following desflurane anesthesia without hemodynamic compromise or delayed awakening in pediatric patients undergoing strabismus surgery.

Opioids have been demonstrated to reduce the incidence of EA effectively after sevoflurane anesthesia (31). Two previous studies have shown that a single bolus dose of fentanyl (either 1 or $2 \mu \mathrm{g} / \mathrm{kg}$ ) reduced the incidence of severe EA following sevoflurane anesthesia $(32,33)$. The intravenous administration of a single dose of $0.15 \mu \mathrm{g} / \mathrm{kg}$ sufentanil just before skin incision significantly decreased the incidence of EA in children undergoing inguinal hernia repair under sevoflurane anesthesia compared with a single dose of $1.5 \mu \mathrm{g} / \mathrm{kg}$ fentanyl (34). Although the dosage of opioids is different $(0.2 \mu \mathrm{g} / \mathrm{kg}$ sufentanil vs. $1.5 \mu \mathrm{g} / \mathrm{kg}$ fentanyl), Bedirli et al (8) arrived at the same conclusion for adenotonsillectomy. In the present study, sufentanil $(0.2 \mu \mathrm{g} / \mathrm{kg})$ and fentanyl $(2 \mu \mathrm{g} / \mathrm{kg})$ were administered intravenously $30 \mathrm{~min}$ prior to the end of surgery. The present study aimed to exclude the influence of post-operative pain on EA and decrease the incidence of EA. Due to regional block, opioids and nonsteroidal anti-inflammatory agents have been reported to decrease the incidence of EA $(35,36)$. However, EA still occurs, even after adequate pain treatment or procedures that are not associated with pain (37). Furthermore, findings from the present study indicated that the mean maximum PAED and CHIPPS scores were significantly lower in group DS than in group SF. The above results demonstrate that DEX combined with sufentanil may alleviate the pain following cleft palate surgery in children and reduce the EA following sevoflurane anesthesia more effectively than saline combined with fentanyl.

In the present study, a significantly increased number of children in group DS required rescue fentanyl doses of $1 \mu \mathrm{g} / \mathrm{kg}$ compared with children in group SF [5 (10.8\%) vs. 29 (61.7\%), respectively]. This was likely due to the fact that the analgesic effectiveness of sufentanil is 10 times than that of fentanyl, which has a shorter duration of action (38). Furthermore, compared with saline, DEX provided the effect of analgesia and sedation. Sufentanil provides a fast onset due to its high lipid solubility (39). The clearance of sufentanil in children was twice as rapid as described in adults and adolescence (40). In the present study, remifentanil TCI was utilized for the maintenance of anesthesia, as remifentanil TCI reduces the emergence of coughing from general anesthesia more effectively than a single-dose of DEX (41). However, a single-dose of DEX is able to maintain respiratory and hemodynamic stability during emergence (42).

DEX, a selective $\alpha-2$ adrenoceptor agonist, has sedative, analgesic and anxiolytic effects after intravenous administration (43). DEX also produces dose-dependent HR and blood pressure reductions $(44,45)$. In the present study, compared with group DS and the DS baseline, HR and MAP were significantly increased in group SF immediately following tracheal intubation and extubation. HR and MAP of T2 (before induction) significantly increased in group DS compared with the DS baseline. A study by Kim et al (31) concluded that a $1 \mu \mathrm{g} / \mathrm{kg}$-dose of intravenous DEX reduced EA following sevoflurane anesthesia in children undergoing magnetic resonance imaging. The bolus administration of DEX in this dose was safe and did not lead to an increased incidence of side effects (46). An intraoperative infusion of DEX combined with inhalation anesthetics provided satisfactory intraoperative conditions for tonsillectomy and adenoidectomy without adverse hemodynamic effects (47). The study also indicated that postoperative opioid requirements were significantly reduced, and the incidence and duration of severe EA was lower, with fewer patients having desaturation episodes. Furthermore, the number of rescue fentanyl doses of $1 \mu \mathrm{g} / \mathrm{kg}$ in the present study was significantly lower in the DS group than that of the SF group in the present study. A study by Kim et al (48) demonstrated that DEX appeared to be a safe and effective alternative to reduce the occurrence of early EA in children after tonsillectomy and that the mechanism would be associated with the sedation and analgesia effects provided by DEX. For prevention of EA after desflurane anesthesia for 50 and $95 \%$ of children undergoing tonsillectomies or adenoidectomies, administration of 0.25 or $0.38 \mu \mathrm{g} / \mathrm{kg}$ DEX has been suggested (31). DEX produces an analgesic effect; therefore, it may reduce postoperative opioid use and the incidence of opioid-related complications, such as respiratory depression, nausea and pruritus $(49,50)$.

The present study had some limitations. Firstly, for the consideration of safety and shortage of personnel, there were only two groups in the present study. Four groups would have improved the study design and may have achieved a superior result to demonstrate that DEX combined with sufentanil is able to optimize sevoflurane anesthesia in children. Experiment design will be optimized in our further research. Secondly, the type of surgery was limited. The reason why palate repair surgery was studied instead of alternative surgeries, such as adenotonsillectomy or cleft lip repair, is due to the increased irritation associated with cleft palate repair surgery (51). Thirdly, the dose of DEX $(0.5 \mu \mathrm{g} / \mathrm{kg})$ used in the present study was selected based on doses cited in previous studies $(52,53)$. A higher dose of DEX 
may be more effective to decrease EA; however, it may also cause other problems, such as dose-dependent HR and blood pressure reductions or a delay in the restoration of consciousness (54).

In conclusion, we believe that $\operatorname{DEX}(0.5 \mu \mathrm{g} / \mathrm{kg})$ administered intravenously $10 \mathrm{~min}$ prior to induction of anesthesia combined with sufentanil $(0.2 \mu \mathrm{g} / \mathrm{kg})$ administered intravenously prior to incision and $30 \mathrm{~min}$ before the end of surgery may effectively inhibit intubation and extubation response of children receiving sevoflurane anesthesia for cleft palate repair surgery. This combined DEX and sufentanil administration may also maintain greater hemodynamic stability, reduce the incidence of EA, reduce the dose of remifentanil required and reduce the number of $1 \mu \mathrm{g} / \mathrm{kg}$ fentanyl administrations. Additionally, the present study demonstrated that this treatment did not increase the time to extubation or the recovery time.

\section{Acknowledgements}

The present study was funded by the National Natural Science Fund, China (grant nos. 81571936, 81401626 and 81500947).

\section{References}

1. Raj S: The timing of primary cleft lip and palate surgery-the experience of a craniofacial center in South India. Brit J Oral Max Surg 49: S91-S92, 2011.

2. Klingmann A: Anesthetic management of pediatric cleft lip and cleft palate repair. Anaesthesist 55: 93-94, 2006 (In German).

3. Milić M, Goranović T and Knezević P: Complications of sevoflurane-fentanyl versus midazolam-fentanyl anesthesia in pediatric cleft lip and palate surgery: A randomized comparison study. Int J Oral Maxillofac Surg 39: 5-9, 2010.

4. Nguyen C, Hernandez-Boussard T, Davies SM, Bhattacharya J, Khosla RK and Curtin CM: Cleft palate surgery: An evaluation of length of stay, complications and costs by hospital type. Cleft Palate Craniofac J 51: 412-419, 2014.

5. Silva LM, Braz LG and Módolo NS: Emergence agitation in pediatric anesthesia: Current features. J Pediatr (Rio J) 84 $107-113,2008$

6. Goa KL, Noble S and Spencer CM: Sevoflurane in paediatric anesthesia: A review. Paediatr drugs 1: 127-153, 1999.

7. Hatch DJ: New inhalation agents in paediatric anesthesia. Br J Anaesth 83: 42-49, 1999.

8. Bedirli N, Akçabay M and Emik U: Tramadol vs dexmedetomidine for emergence agitation control in pediatric patients undergoing adenotonsillectomy with sevoflurane anesthesia: Prospective randomized controlled clinical study. Bmc Anesthesiology 17: 41, 2017.

9. Use T, Nakahara H, Kimoto A, Beppu Y, Yoshimura M, Kojima T and Fukano T: Barbiturate induction for the prevention of emergence agitation after pediatric sevoflurane anesthesia. J Pediatr Pharmacol Ther 20: 385-392, 2015.

10. Cravero J, Surgenor S and Whalen K: Emergence agitation in paediatric patients after sevoflurane anesthesia and no surgery: A comparison with halothane. Paediatr Anaesth 10: 419-424, 2000.

11. Beskow A and Westrin P: Sevoflurane causes more postoperative agitation in children than does halothane. Acta Anesthesiol Scand 43: 536-541, 1999.

12. Sun L, Guo R and Sun L: Dexmedetomidine for preventing sevoflurane-related emergence agitation in children: A meta-analysis of randomized controlled trials. Acta Anesthesiol Scand 58: 642-650, 2014.

13. Li J, Huang ZL, Zhang XT, Luo K, Zhang ZQ, Mao Y, Zhuang XB, Lian QQ and Cao H: Sufentanil reduces emergence agitation in children receiving sevoflurane anesthesia for adenotonsillectomy compared with fentanyl. Chin Med J (Engl) 124 3682-3685, 2011.

14. Theivanayagam S, Lopez KT, Asombang AW, Bechtold ML and Asombang AW: ASA classification prior to endoscopic procedures: A retrospective analysis on accuracy of gastroenterologists. South Med J 110: 79-82, 2017.
15. Barakat AR, Sutcliffe N and Schwab M: Effect site concentration during propofol TCI sedation: A comparison of sedation score with two pharmacokinetic models. Anesthesia 62: 661-666, 2007.

16. Sikich N and Lerman J: Development and psychometric evaluation of the pediatric anesthesia emergence delirium scale. Anesthesiology 100: 1138-1145, 2004.

17. Aono J, Ueda W, Mamiya K, Takimoto E and Manabe M: Greater incidence of delirium during recovery from sevoflurane anesthesia in preschool boys. Anesthesiology 87: 1298-1300, 1997.

18. Aldrete JA: The post-anesthesia recovery score revisited. J Clin Anesth 7: 89-91, 1995.

19. Büttner W and Finke W: Analysis of behavioural and physiological parameters for the assessment of postoperative analgesic demand in newborns, infants and young children: A comprehensive report on seven consecutive studies. Paediatr Anaesth 10: 303-318, 2000

20. Jürgens S: Sevoflurane conscious sedation for MRI scanning. Anesthesia 58: 296-297, 2003.

21. Malviya S, Voepel-Lewis T, Ramamurthi RJ, Burke C and Tait AR: Clonidine for the prevention of emergence agitation in young children: Efficacy and recovery profile. Paediatr Anaesth 16: 554-549, 2006.

22. Keaney A, Diviney D, Harte S and Lyons B: Postoperative behavioral changes following anesthesia with sevoflurane. Pediatr Anesth 14: 866-870, 2004.

23. Cohen IT, Drewsen S and Hannallah RS: Propofol or midazolam do not reduce the incidence of emergence agitation associated with desflurane anesthesia in children undergoing adenotonsillectomy. Paediatr Anaesth 12: 604-609, 2002.

24. Kim KM, Lee KH, Kim YH, Ko MJ, Jung JW and Kang E: Comparison of effects of intravenous midazolam and ketamine on emergence agitation in children: Randomized controlled trial. J Int Med Res 44: 258-266, 2016.

25. Voepel-Lewis T, Malviya S and Tait AR: A prospective cohort study of emergence agitation in the pediatric postanesthesia care unit. Anesth Analg 96: 1625-1630, 2003.

26. Demirbilek S, Togal T, Cicek M, Aslan U, Sizanli E and Ersoy MO: Effects of fentanyl on the incidence of emergence agitation in children receiving desflurane or sevoflurane. anaesthesia. Eur J Anaesthesiol 21: 538-542, 2004

27. Maeda S, Tomoyasu Y, Higuchi H, Ishii-Maruhama M, Egusa M and Miyawaki T: Independent predictors of delay in emergence from general anesthesia. Anesth Prog 62: 8-13, 2015.

28. Özcengiz D, Gunes Y and Ozmete O: Oral melatonin, dexmedetomidine, and midazolam for prevention of postoperative agitation in children. J Anesth 25: 184-188, 2011.

29. Akin A, Bayram A, Esmaoglu A, Tosun Z, Aksu R, Altuntas R and Boyaci A: Dexmedetomidine vs midazolam for premedication of pediatric patients undergoing anesthesia. Paediatr Anaesth 22: 871-876, 2012.

30. Tan Y, Shi Y, Ding H, Kong X, Zhou H and Tian J: $\mu$-Opioid agonists for preventing emergence agitation under sevoflurane anesthesia in children: A meta-analysis of randomized controlled trials. Paediatr Anaesth 26: 139-150, 2016.

31. Kim J, Kim SY, Lee JH, Kang YR and Koo BN: Low-dose dexmedetomidine reduces emergence agitation after desflurane anesthesia in children undergoing strabismus surgery. Yonsei Med J 55: 508-516, 2014.

32. Cravero JP, Beach M, Thyr B and Whalen K: The effect of small dose fentanyl on the emergence characteristics of pediatric patients after sevoflurane anesthesia without surgery. Anesth Analg 97: 364-367, 2003.

33. Galinkin JL, Fazi LM, Cuy RM, Chiavacci RM, Kurth CD, Shah UK, Jacobs IN and Watcha MF: Use of intranasal fentanyl in children undergoing myringotomy and tube placement during halothane and sevoflurane anesthesia. Anesthesiology 93: $1378-1383,2000$.

34. Li X, Zhang Y, Zhou M, Xia Q, Li W and Lu Q: The effect of small dose sufentanil on emergence agitation in preschool children following sevoflurane anesthesia for elective repair of unilateral inguinal hernia. Saudi Med J 34: 40-45, 2013.

35. Weldon BC, Bell M and Craddock T: The effect of caudal analgesia on emergence agitation in children after sevoflurane versus halothane anesthesia. Anesth Analg 98: 321-326, 2004.

36. Aouad MT, Kanazi GE, Siddik-Sayyid SM, Gerges FJ, Rizk LB and Baraka AS: Preoperative caudal block prevents emergence agitation in children following sevoflurane anesthesia. Acta Anaesthesiol Scand 49: 300-304, 2005.

37. Cohen IT, Hannallah RS and Hummer KA: The incidence of emergence agitation associated with desflurane anesthesia in children is reduced by fentanyl. Anesth Analg 93: 88-91, 2001. 
38. Panchgar V, Shetti AN, Sunitha HB, Dhulkhed VK and Nadkarni AV: The effectiveness of intravenous dexmedetomidine on perioperative hemodynamics, analgesic requirement, and side effects profile in patients undergoing laparoscopic surgery under general anesthesia. Anesth Essays Res 11: 72-77, 2017.

39. Lundeberg S and Roelofse JA: Aspects of pharmacokinetics and pharmacodynamics of sufentanil in pediatric practice. Pediatr Anesth 21: 274-279, 2011.

40. Anderson BJ and Meakin GH: Scaling for size: Some implications for paediatric anaesthesia dosing. Paediatr Anaesth 12: 205-219, 2002.

41. Murat G, Yasemin G,Hayri O, Dervis Y and Geylan I: Comparison of dexmedetomidine or remifentanil infusion combined with sevoflurane anesthesia in craniotomy: Hemodynamic variables and recovery. Neurosurg Quart 19: 116-119, 2009.

42. Park JS, Kim KJ, Lee JH, Jeong WY and Lee JR: A randomized comparison of remifentanil target-controlled infusion versus dexmedetomidine single-dose administration: A better method for smooth recovery from general sevoflurane anesthesia. Am J Ther 23: e690-e696, 2016.

43. Talke PO, Caldwell JE, Richardson CA, Kirkegaard-Nielsen H and Stafford M: The effects of dexmedetomidine on neuromuscular blockade in human volunteers. Anesth Analg 88: 633-639, 1999.

44. Unlugenc $\mathrm{H}$, Gunduz $\mathrm{M}$, Guler $\mathrm{T}$, Yagmur $\mathrm{O}$ and Isik $\mathrm{G}$ : The effect of preanaesthetic administration of intravenous dexmedetomidine on postoperative pain in patients receiving patient-controlled morphine. Eur J Anaesthesiol 22: 386-391, 2005.

45. Arain SR, Ruehlow RM, Uhrich TD and Ebert TJ: The efficacy of dexmedetomidine versus morphine for postoperative analgesia after major inpatient surgery. Anesth Analg 98: 153-158, 2004

46. Isik B, Arslan M, Tunga AD and Kurtipek O: Dexmedetomidine decreases emergence agitation in pediatric patients after sevoflurane anesthesia without surgery. Pediatr Anesth 16: 748-753, 2006.
47. Patel A, Davidson M, Tran MC, Quraishi H, Schoenberg C, Sant M, Lin A and Sun X: Dexmedetomidine infusion for analgesia and prevention of emergence agitation in children with obstructive sleep apnea syndrome undergoing tonsillectomy and adenoidectomy. Anesth Analg 111: 1004-1110, 2010.

48. Kim HS, Byon HJ, Kim JE, Park YH, Lee JH and Kim JT: Appropriate dose of dexmedetomidine for the prevention of emergence agitation after desflurane anesthesia for tonsillectomy or adenoidectomy in children: Up and down sequential allocation. BMC Anesthesiol 15: 79, 2015.

49. Messerer B, Gutmann A, Weinberg A and Sandner-Kiesling A: Implementation of a standardized pain management in a pediatric surgery unit. Pediatr Surg Int 26: 879-889, 2010.

50. Tufanogullari B, White PF, Peixoto MP, Kianpour D, Lacour T, Griffin J, Skrivanek G, Macaluso A, Shah M and Provost DA: Dexmedetomidine infusion during laparoscopic bariatric surgery: The effect on recovery outcome variables. Anesth Analg 106: 1741-1748, 2008.

51. Swennen G, Berten JL, Schliephake H, Treutlein C, Dempf R, Malevez C and De MA: Midfacial morphology in children with unilateral cleft lip and palate treated by different surgical protocols. Int J Oral Maxillofac Surg 31: 13-22, 2002.

52. Guler G, Akin A, Tosun Z, Eskitascoglu E, Mizrak A and Boyaci A: Single-dose dexmedetomidine attenuates airway and circulatory reflexes during extubation. Acta Anaesthesiol Scand 49: 1088-1091, 2005.

53. Turan G, Ozgultekin A, Turan C, Dincer E and Yuksel G: Advantageous effects of dexmedetomidine on haemodynamic and recovery responses during extubation for intracranial surgery. Eur J Anaesthesiol 25: 816-820, 2008.

54. Kato J, Ogawa Y, Kojima W, Aoki K, Ogawa S and Iwasaki K: Cardiovascular reflex responses to temporal reduction in arterial pressure during dexmedetomidine infusion: A double-blind, randomized and placebo-controlled study. Br J Anaesth 103: $561-565,2009$ 